\title{
Spatial distribution of maize in response to climate change in northeast China during 1980-2010
}

\author{
LI Zhengguo ${ }^{1}$, TAN Jieyang ${ }^{1,2}$, TANG Pengqiin ${ }^{1}$, CHEN Hao ${ }^{1}$, ZHANG Li $^{1}$, \\ LIU Han', WU Wenbin ${ }^{1}$, TANG Huajun ${ }^{1},{ }^{*}$ YANG Peng ${ }^{1},{ }^{*}$ LIU Zhenhuan ${ }^{3}$ \\ 1. Chinese Academy of Agricultural Sciences, Key Laboratory of Agri-informatics, Ministry of Agriculture/Insti- \\ tute of Agricultural Resources and Regional Planning, Beijing 100081, China; \\ 2. Hunan Academy of Agricultural Sciences, Institute of Agricultural Economics and Regional Planning, \\ Changsha 410125, China; \\ 3. Sun Yat-sen University, School of Geography and Planning, Guangzhou 510275, China
}

\begin{abstract}
Based on county-level crop statistics and other ancillary information, spatial distribution of maize in the major maize-growing areas (latitudes $39^{\circ}-48^{\circ} \mathrm{N}$ ) was modelled for the period $1980-2010$ by using a cross-entropy-based spatial allocation model. Maize extended as far north as the northern part of the Lesser Khingan Mountains during the period, and the area sown to maize increased by about 5 million ha. More than half of the increase occurred before 2000 , and more than $80 \%$ of it in the climate transitional zone, where the annual accumulated temperature (AAT) was $2800-3400{ }^{\circ} \mathrm{C} \cdot \mathrm{d}$. Regions with AAT of $3800-4000{ }^{\circ} \mathrm{C} \cdot \mathrm{d}$ became more important, accounting for more than $25 \%$ of the increase after 2000 . The expansion of maize was thus closely related to warming, although some variation in the distribution was noticed across zones in relation to the warming, indicating that maize in northeast China may have adapted successfully to the warming by adjusting its spatial distribution to match the changed climate.
\end{abstract}

Keywords: climate warming; regional response; spatial pattern; Zea mays; China

\section{Introduction}

Climate change, through its impacts on agriculture, is expected to affect crop production dramatically and worldwide in the present century (IPCC, 2007; IPCC, 2013). Not all the impacts are likely to be adverse: in fact, crop production may even benefit from future warming if cropping systems are suitably adapted, especially at higher latitudes (De Jong et al., 2001; Robert et al., 2003; Li et al., 2015). Many specific cropping practices have been recommended as active adaptations to warming, such as adjusting crop phenophases, that is the sowing and harvesting dates (Rosenzweig and Hillel, 1998; Lobell et al., 2008; Li et al.,

Received: $2015-05-20$ Accepted: $2015-07-28$

Foundation: National Natural Science Foundation of China, No.41171328, No.41201184, No.41101170

Author: Li Zhengguo, PhD and Associate Professor, specialized in remote sensing, climate change and food security.

E-mail: lizhengguo@caas.cn

"Corresponding author: Liu Zhenhuan, PhD, E-mail: liuzhh39@mail.sysu.edu.cn

Peng Yang, PhD, E-mail: yangpeng@caas.cn 
2012), and adopting new cultivars with a longer growing season (Jørgen and Marco, 2002; Ogden and Innes, 2008). Since both climate change and agronomic improvement are long-term and gradual processes, the present crop distribution may reflect an active and gradual adaptation to warming over the past few decades (Lobell et al., 2008; Tao and Zhang, 2010; Yang et al., 2015). A better understanding of such changes in crop distribution as a result of the warming will be useful in making strategic decisions on future crop production and food security (Nicholls, 1997; Piao et al., 2010; Chen et al., 2011; Lobell et al., 2011).

Northeast China (NEC) is one of the most important grain-producing regions of the country and represents more than 8 million ha sown to maize (Zea mays), contributing more than $30 \%$ of China's total maize production (NBSC, 2010). Of all the regions in China, NEC has experienced the obvious increases in temperature (Liu et al., 2004; Chen et al., 2012): the average surface temperature in the region went up at a rate of $0.38^{\circ} \mathrm{C}$ per decade over the past five decades (Jin et al., 1996; Liu et al., 2009). A sustained increase in temperature over the season is believed to affect the growth, phenophases (that is dates for sowing, seedling emergence, maturity, etc.), and yield of maize (Tao et al., 2008a, 2008b; Chen et al., 2011). Jin et al. (2008) believed that local maize varieties will change from early-maturing ones to mid- and late-maturing ones, with a longer growing season, as a result of climate change in NEC. Relevant studies thus far have shown that over the past 30 years in NEC, the growth period of maize has been advancing (in other words, temperatures of $7^{\circ} \mathrm{C}$ or above and of $10^{\circ} \mathrm{C}$ or above are being reached earlier in the year), leading to a higher total annual accumulated temperature (AAT) (Liu et al., 2009; Jia and Guo, 2010; Chen et al., 2012; Li et al., 2014). Earlier studies, which mostly focused on yield, have shown that climate warming may lead to greater maize yields in NEC (Kenny et al., 1993; Carter et al., 1996; Yang et al., 2007; Tao et al., 2008b; Chen et al., 2011; Sun and Huang, 2011; Tao and Zhang, 2011; Chen et al., 2012; Liu Z J et al., 2013). However, a further understanding of how the areas sown to maize have changed - both in terms of their extent and their location-has implications for food security and resource management that are not evident from yield analyses alone. For example, the location and extent of the area under maize are critical to more efficient allocation of natural resources, which are costly, if not impossible, to transport. Infrastructure development helps expand or develop natural resources, and may be either a precursor or a response to changes in the spatial distribution of crops (Li et al., 2015). Such changes with reference to maize may affect, and in turn be affected by, the natural ecosystem as well (Piao et al., 2010). Regional temperature and precipitation patterns may affect such spatial changes, particularly given that nearly all the maize grown in NEC is rain-fed (Tao et al., 2006). Less well understood, however, is the mechanism by which long-term changes in temperature and precipitation drive the changes in the extent and location of maize cultivation.

To investigate the spatio-temporal changes in the distribution of maize cultivation, it is essential to know where and when maize has been grown over the past few decades. Although census-based crop data sets are available, their resolution, even at the county level, is too coarse for detailed spatial analysis (Monfreda et al., 2008). Data from satellite imagery are preferable because of the high spatial resolution and wide spatial and temporal coverage (Xiao et al., 2005). However, satellite images can show only the dominant land-cover category and seldom distinguish between crop over a large region (Ramankutty et al., 2008). 
Developing spatial datasets of the geographic distribution of crop at the pixel level is essential for studying the changes in spatial distribution of crop in response to warming (You et al., 2009b; Liu Z H et al., 2013). Recently, however, a spatial allocation model has been developed and used for modelling crop distribution over the last few decades at a resolution of 5" (Tan et al., 2014a; Tan et al., 2014b; Anderson et al., 2015).

In the present study, the area sown to maize across NEC over the period 1980-2010 was modelled to study the spatio-temporal changes in the distribution of maize cultivation and to relate them to global warming to gain useful insights into such changes. A more thorough understanding of the crop's dynamics will guide policymaking for agriculture not only in China but also in maize-growing areas at higher latitudes worldwide.

\section{Study area and materials}

\subsection{Study area}

Northeast China covers $791,800 \mathrm{~km}^{2}$, of which cropland occupies $264,400 \mathrm{~km}^{2}$, accounting for $16.5 \%$ of the total arable land in China (NBSC, 2010). The region plays a vital role in China's economic development as one of the most important bases of food grains (e.g. maize and rice) and other economic crops (e.g. soybean and sugar beet). Geographically, NEC extends from $118^{\circ} 53^{\prime}$ to $135^{\circ} 05^{\prime} \mathrm{E}$ and from $38^{\circ} 43^{\prime}$ to $53^{\circ} 33^{\prime} \mathrm{N}$ and comprises three provinces, namely Heilongjiang, Jilin and Liaoning (Figure 1). Over most of the region, AAT $\left(>0^{\circ} \mathrm{C}\right)$ is $2500-4000{ }^{\circ} \mathrm{C} \cdot \mathrm{d}$, average summer temperatures are $20-25^{\circ} \mathrm{C}$, the frost-free period is 140

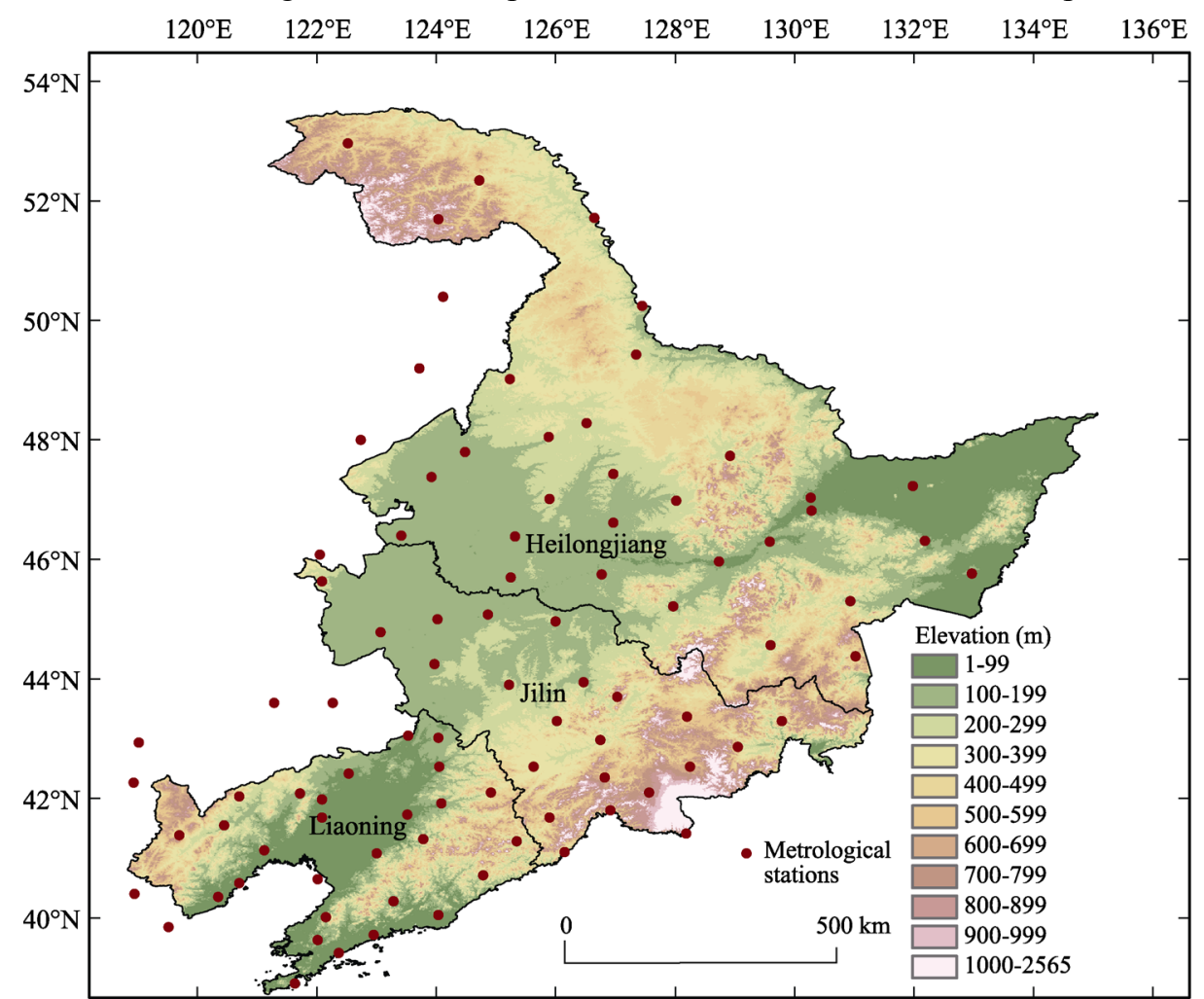

Figure 1 Meteorological stations in northeast China. Red dots represent meteorological stations; the gradient indicates elevation; and black lines mark province boundaries. 
170 days, and annual precipitation is $500-800 \mathrm{~mm}, 60 \%$ of which is received mainly during July-September, coinciding with the growing season of maize (Liu et al, 2009). As mentioned earlier, NEC has been undergoing a significant warming over the past few decades: annual sunshine hours have decreased by 40.6 hours per decade over the past five decades (Gao and Liu, 2011), and the daily minimum temperature has risen more sharply than the daily maximum temperature, thus markedly narrowing the diurnal temperature range (Liu Z $\mathrm{J}$ et al., 2013).

\subsection{Data used}

The relevant meteorological data for the period 1980-2010 were obtained from China Meteorological Administration (CMA, 2010) and came from 84 meteorological stations in NEC and 10 stations in the surrounding area. The dataset contained the daily maximum, minimum, and average temperatures. Data on the sown area under maize in NEC after 1980 were collected from the Planting Information Network of China (PINC, 2010).

In addition, data on national land-use product (NLUD) of China for the 1980s, 1990s, and 2000s were provided by the Chinese Academy of Sciences (CAS), which are also available online as part of the Data Sharing Infrastructure of Earth System Science (www.geodata.cn). This dataset includes 6 land-cover types (forest, grassland, cropland, city, wetland and water, and desert) and 25 subclasses with a resolution of $100 \mathrm{~m}$ and is produced from images obtained by remote sensing with a spatial resolution of $30 \mathrm{~m}$, visual interpretation, field surveys, and other auxiliary information (Liu et al., 2002; Zhang et al., 2014).

\section{Methods}

\subsection{Crop data and meteorological data pre-processing}

In general, the first day on which the average temperature reaches $7^{\circ} \mathrm{C}$ is suitable for sowing maize in NEC, and the biological minimum temperature for the growth of maize in this region is $10^{\circ} \mathrm{C}$ (Jia and Guo, 2010). We defined the first day that recorded a temperature greater than $10^{\circ} \mathrm{C}$ as the starting date of the growth season and the first day of frost (daily average temperature below $2^{\circ} \mathrm{C}$ ) as the last date, which marked the end of the growth season. When calculating the threshold temperatures $\left(10^{\circ} \mathrm{C}\right.$ and $\left.2^{\circ} \mathrm{C}\right)$ for each station, a 5-day moving average was used. The theoretical dates on which maize was sown and harvested were taken as the days from which the temperatures stabilized above $10^{\circ} \mathrm{C}$ and below $2^{\circ} \mathrm{C}$, respectively, and the number of days between these two dates was defined as the growth period that coincided with the desirable temperatures, i.e. the period over which temperatures were suitable for the growth of maize in a given region. Lastly, we calculated AAT in the growth period thus defined during 1980-2010. For analysing the spatial distribution of AAT, we used inverse distance weighting (IDW) interpolation provided by ArcGIS 10.0 package. Statistical significance was tested by using the two-tailed $t$-test.

\subsection{Mapping the spatial distribution of maize}

Recently, some pixel-based crop maps have been developed by combining agricultural inventory data and land-cover data from remote sensing (Monfreda et al., 2008; Ramankutty et al., 2008; Portmann et al., 2010). However, all these maps provide cropping areas at a 
spatial resolution of $5^{\prime} \times 5^{\prime}$ in 2000 on a global scale, which is insufficient for dynamic detection and detailed spatial analysis. Therefore, we used the spatial production allocation model (SPAM) developed by the International Food Policy Research Institute (IFPRI) and the Chinese Academy of Agricultural Sciences (CAAS) for mapping the spatial distribution of maize (You et al., 2014; Tan et al., 2014a; Anderson et al., 2015). The input data included county-scale crop production statistics for 1980-2010, maps of irrigated areas, biophysical crop suitability assessments, population density, secondary data on irrigation and rain-fed production systems, cropping intensity, and crop prices. All the information was compiled and integrated to generate 'prior' estimates of the spatial distribution of crops. These estimates were then fed into an optimization model that uses cross-entropy principles and accounting constraints for area and yield to allocate crops to individual pixels of a GIS database. The results for each pixel (a grid of $5^{\prime} \times 5^{\prime}$ ) represented the areas sown to maize in 1980, 1990, 2000, and 2010.

\subsection{Spatial validation of maize distribution}

To validate the results from the SPAM maps, they were compared with the NLUD maps for 2005 pixel by pixel as follows (Tan et al., 2014b). (1) Pixels that showed no cropland or crop in both the maps were marked as empty. These pixels indicate areas that were not under cultivation. (2) Pixels with cropland, but not maize (NLUD $>0$ and SPAM $=0$ ), were defined as no-existing-maize. These pixels represent cropland that was not under maize, either because some other crop had replaced maize or because cultivation had been abandoned. (3) Pixels allocated to maize but did not correspond to cropland (NLUD $=0$ and SPAM $>0$ ) were defined as mis-allocated and thus represent misallocation by SPAM. (4) Pixels allocated more to maize than to cropland (NLUD $>0$ and SPAM $>0$, but SPAM $>$ NLUD) were defined as overestimated. (5) Pixels with appropriate areas for maize (NLUD $>0$, SPAM $>0$, and SPAM $<$ NLUD) were defined as those that can be reasonably assumed to have been under maize.

\subsection{Zoning of maize maturity types}

To understand the spatial variation in maize cultivation in response to warming during 1980-2010, we developed a zoning scheme based on AAT to categorize maize into 6 categories based on the time taken to maturity (Table 1). Two primary categories of the zones were established - stable and transitional-in terms
Table 1 Maturity types of maize based on annual accumulated temperatures (AAT)

\begin{tabular}{lc}
\hline \multicolumn{1}{c}{ Maturity type } & AAT $\left({ }^{\circ} \mathrm{C} \cdot \mathrm{d}\right)$ \\
\hline Extremely early maturing (EEM) & $2100-2200$ \\
Early maturing (EM) & $2200-2400$ \\
Early-mid maturing (EMM) & $2400-2550$ \\
Mid-maturing (MM) & $2550-2700$ \\
Mid-late maturing (MLM) & $2700-2800$ \\
Late maturing (LM) & $2800-3100$ \\
\hline
\end{tabular}

of the response to warming (Figure 2). In the zones with relatively stable thermal conditions, the suitable maturity types remained unchanged: extremely early maturing (EEM), early maturing (EM), early-mid maturing (EMM), mid-maturing (MM), mid-late maturing (MLM), and late maturing (LM). In the transitional zones with a marked rise in temperatures, the suitable maturity types changed because of the warming: they either became unsuitable to extremely-early maturing types (UST $\rightarrow$ EEM) or switched to late- maturing types, from 
extremely- early-maturing to early maturing $(\mathrm{EEM} \rightarrow \mathrm{EM})$, from early maturing to mid-maturing $(\mathrm{EM} \rightarrow \mathrm{MM})$, from mid-maturing to mid-late maturing $(\mathrm{MM} \rightarrow \mathrm{MLM})$, and from mid-late maturing to late maturing $(\mathrm{MLM} \rightarrow \mathrm{LM})$.

\section{Results}

\subsection{Mapping and validation of maize distribution}

For validating the results, as mentioned earlier, the areas indicated by SPAM were compared with those in the NLUD-2005 map at the pixel level (Figure 3). Mis-allocated pixels were few, found mostly in the lower Liaohe Plain, and accounted for only $0.58 \%$ of the total pixels and only $0.14 \%$ of the area indicated by SPAM. The overestimated pixels were distributed sporadically and accounted for $2.39 \%$ of the total pixels and $1.96 \%$ of the SPAM area. Pixels were reasonable to assume as being under maize by the SPAM results occupied $70.8 \%$ of the total pixels and accounted for $97.9 \%$ of the SPAM area. Thus, the results confirmed that the areas as identified by SPAM are accurate and the method is suitable for analysing the spatial distribution of maize in NEC.

The results from SPAM for each pixel were used to estimate the change ratio in area under maize in the 1980s, 1990s, and 2000s, that can be found in a previously published paper by Tan et al. (2014a). From 1980 to 2010, at more than 0.16 million ha per year, maize area in NEC increased by about 5 million

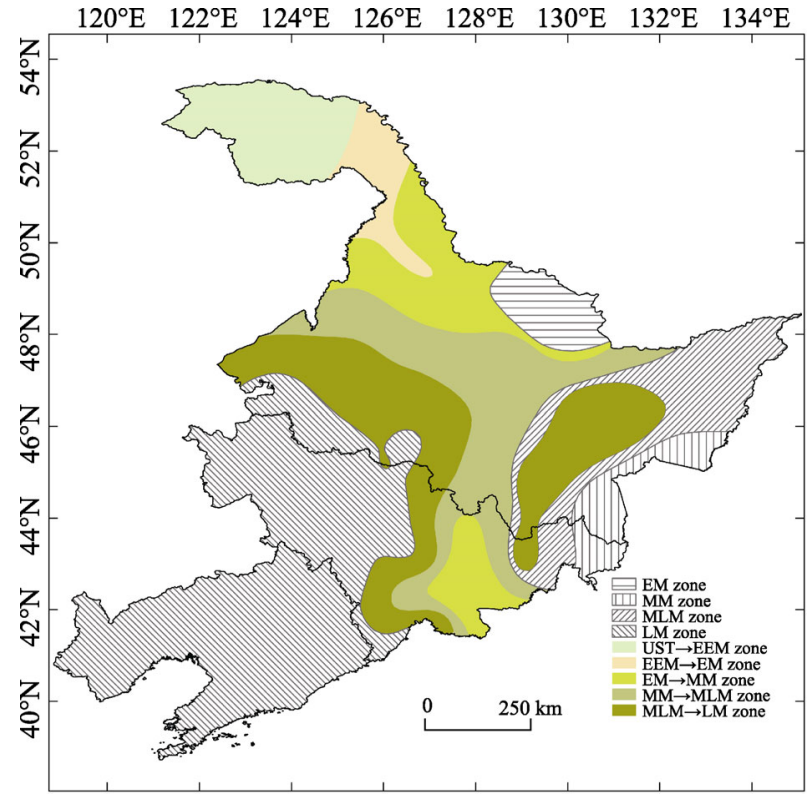

Figure 2 Spatial zoning of maize maturity types during 1980 2010. Note: Stable climatic zones (shaded part) suited to varieties of maize classified by the temperature taken to reach maturity: (a) early maturing (EM), (b) mid-maturing (MM), (c) mid-late maturing (MLM), and (d) late maturing (LM). Transitional climatic zones (colored part) suited to varieties of maize classified by the temperature taken to reach maturity: (e) unsuitable for cultivation of maize to extremely early maturing (UST $\rightarrow$ EEM), (f) extremely early maturing to early maturing $(\mathrm{EEM} \rightarrow \mathrm{EM})$, $(\mathrm{g})$ early to mid-maturing $(\mathrm{EM} \rightarrow \mathrm{MM}),(\mathrm{h})$ mid- to mid-late maturing $(\mathrm{MM} \rightarrow$ MLM), and (i) mid-late to late maturing (MLM $\rightarrow$ LM).

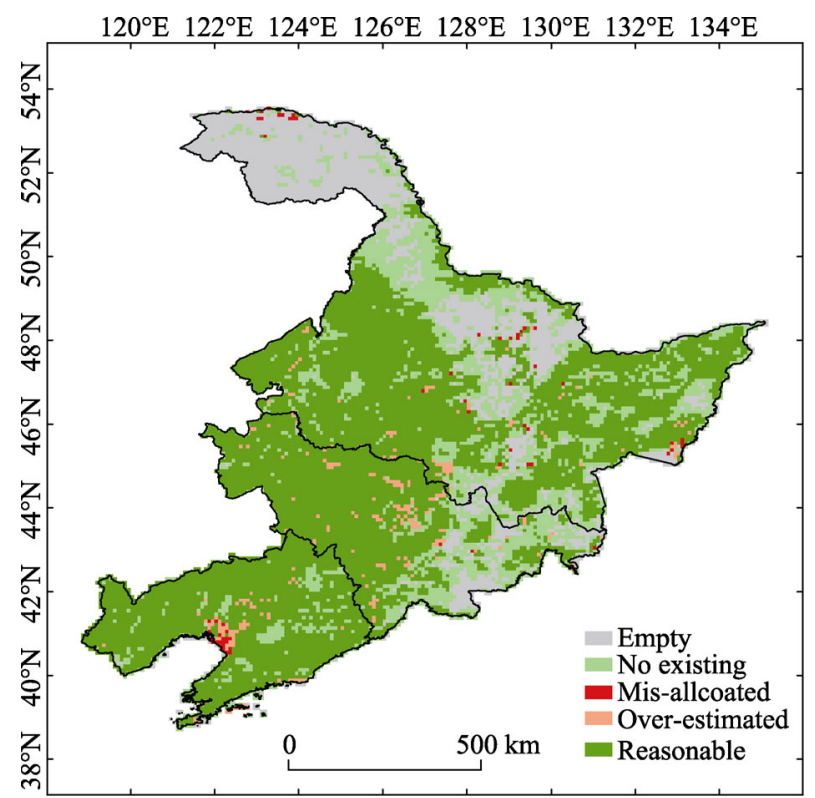

Figure 3 Validation of maize distribution by comparing with the NLUD map in 2005 
ha. In the 1980s, regions that recorded a significant increase were mainly concentrated in the eastern part of the Songliao Plain whereas those that recorded a decrease were in the middle-lower Liaohe Plain and the southern part of the Songnen Plain. In the 1990s, the northern part of the Songnen Plain, the southern part of the Lesser Khingan Mountains, and the middle-upper Sanjiang Plain recorded an increase and the northern part of the Liaohe Plain and the western part of the Songnen Plain recorded a significant decrease. Since 2000, areas to the east of the Liaohe Plain, Sanjiang Plain, and the hilly and corridor zones in the western part of Liaoning have recorded an increase and parts of the eastern Songnen Plain and the northern Liaohe Plain have recorded a decrease.

4.2 Variations in the spatial dischanges in temperature

The average values of AAT increased gradually, from $3099{ }^{\circ} \mathrm{C} \cdot \mathrm{d}$ in the 1980 s to $3264{ }^{\circ} \mathrm{C} \cdot \mathrm{d}$ in the 1990 s to $3274{ }^{\circ} \mathrm{C} \cdot \mathrm{d}$ in the $2000 \mathrm{~s}$. The increasing trend was seen at 76 out of 94 stations (close to $90 \% ; P<0.05$; Figure 4). The overall increase was

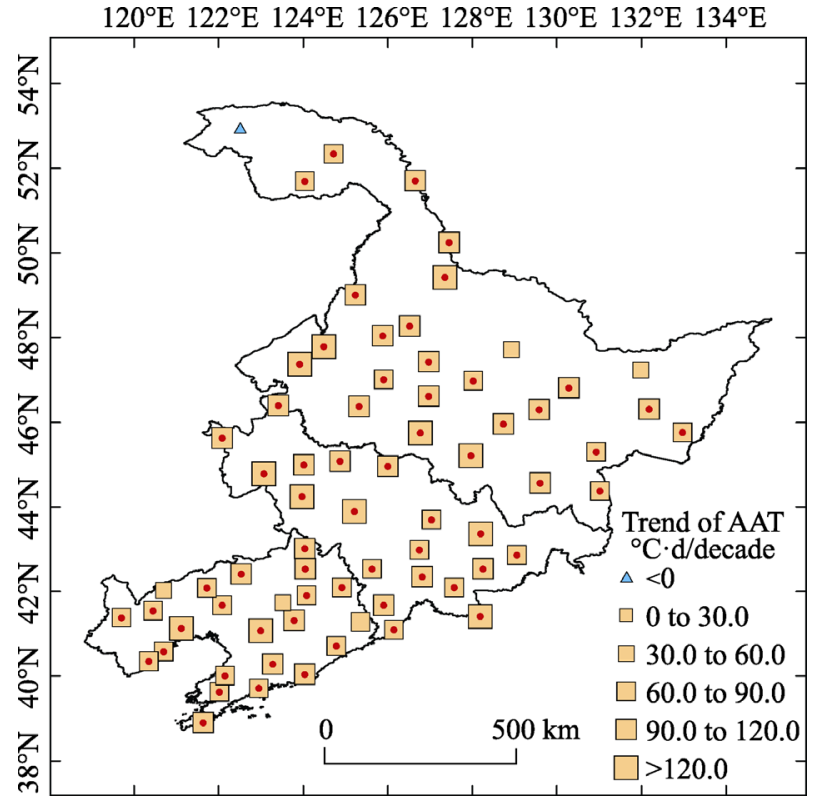

Figure 4 Spatio-temporal changes in AAT during 1980-2010 in NEC. Red dots mark a change significant at 0.05 level. about $95{ }^{\circ} \mathrm{C} \cdot \mathrm{d}$ whereas the rate of increase per decade ranged from $33{ }^{\circ} \mathrm{C} \cdot \mathrm{d}$ to $203{ }^{\circ} \mathrm{C} \cdot \mathrm{d}$. The most significant increase was in the Songnen Plain and the central Lesser Khingan Mountains. The interpolated values of AAT were grouped into different classes at intervals of 200 ${ }^{\circ} \mathrm{C} \cdot \mathrm{d}$. The number of stations in AAT classes below $2800{ }^{\circ} \mathrm{C} \cdot \mathrm{d}$, located mostly in the Songnen and Sanjiang plains, decreased during 1980-2010 whereas that in AAT classes above

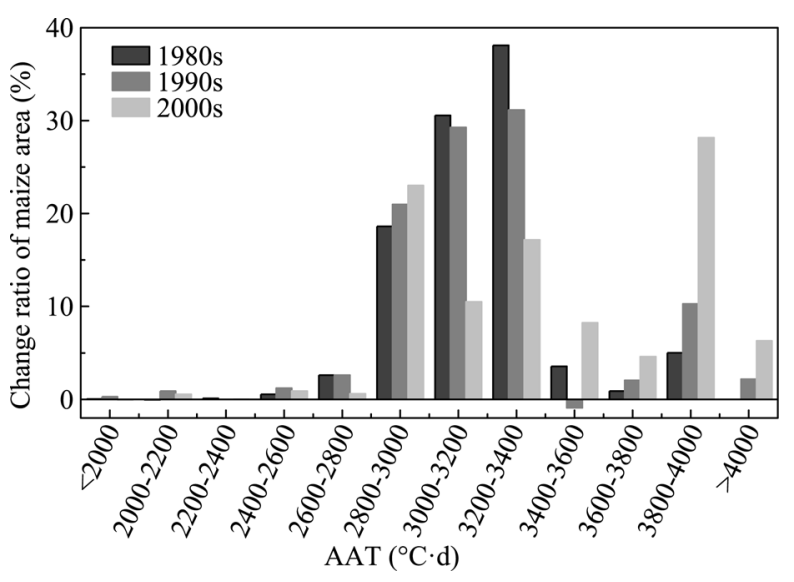

Figure 5 Changes in area sown to maize with annual accumulated temperature in the 1980s, 1990s, and 2000s
3400 increased from $15 \%$ to $25 \%$. Across NEC, the number of stations in AAT classes below $2600{ }^{\circ} \mathrm{C} \cdot \mathrm{d}$ decreased from $20 \%$ to $11 \%$.

Changes in the spatial distribution of areas sown to maize and with AAT in the range of $1800-4000{ }^{\circ} \mathrm{C} \cdot \mathrm{d}$ were analysed at the pixel level for each decade from 1980 to 2010 by summing the areas at intervals of $200^{\circ} \mathrm{C}$. More than $95 \%$ of the locations that recorded an increase in the area sown to maize were in regions with AAT greater than $2800^{\circ} \mathrm{C} \cdot \mathrm{d}$ (Figure 5). In 
the regions with AAT from 3000 to $3400{ }^{\circ} \mathrm{C} \cdot \mathrm{d}$, although the total area sown to maize increased, the extent of increase over the previous decade showed a declining trend: in the $1980 \mathrm{~s}$, the increase was as much as $68.7 \%$ but it declined to $60.4 \%$ in the $1990 \mathrm{~s}$ and fell further to $27.7 \%$ in the $2000 \mathrm{~s}$. In all the other AAT regions, on the other hand, both the total area and the extent of increase over the previous decade showed a rising trend-by $24.5 \%$ in the $1980 \mathrm{~s}, 35.5 \%$ in the $1990 \mathrm{~s}$, and $62.1 \%$ for in the $2000 \mathrm{~s}$.

\subsection{Spatial distribution of maize in response to warming}

Changes in spatial distribution of maize in response to warming from 1980 to 2010 were analysed by dividing the area under maize into zones based on the temperature taken by the maize varieties to reach maturity (see Table 1 and Figure 2). In the 1980s, the area under maize expanded mostly in the MLM $\rightarrow$ LM and LM zones, in the central part of Jilin and the southern part of Heilongjiang (Figure 6a). During this period, the total area under maize increased by about 1.3 million ha, in which the contribution of zones with stable thermal conditions was less than $10 \%$; the rest of the expansion came from the MLM $\rightarrow$ LM transitional zone.
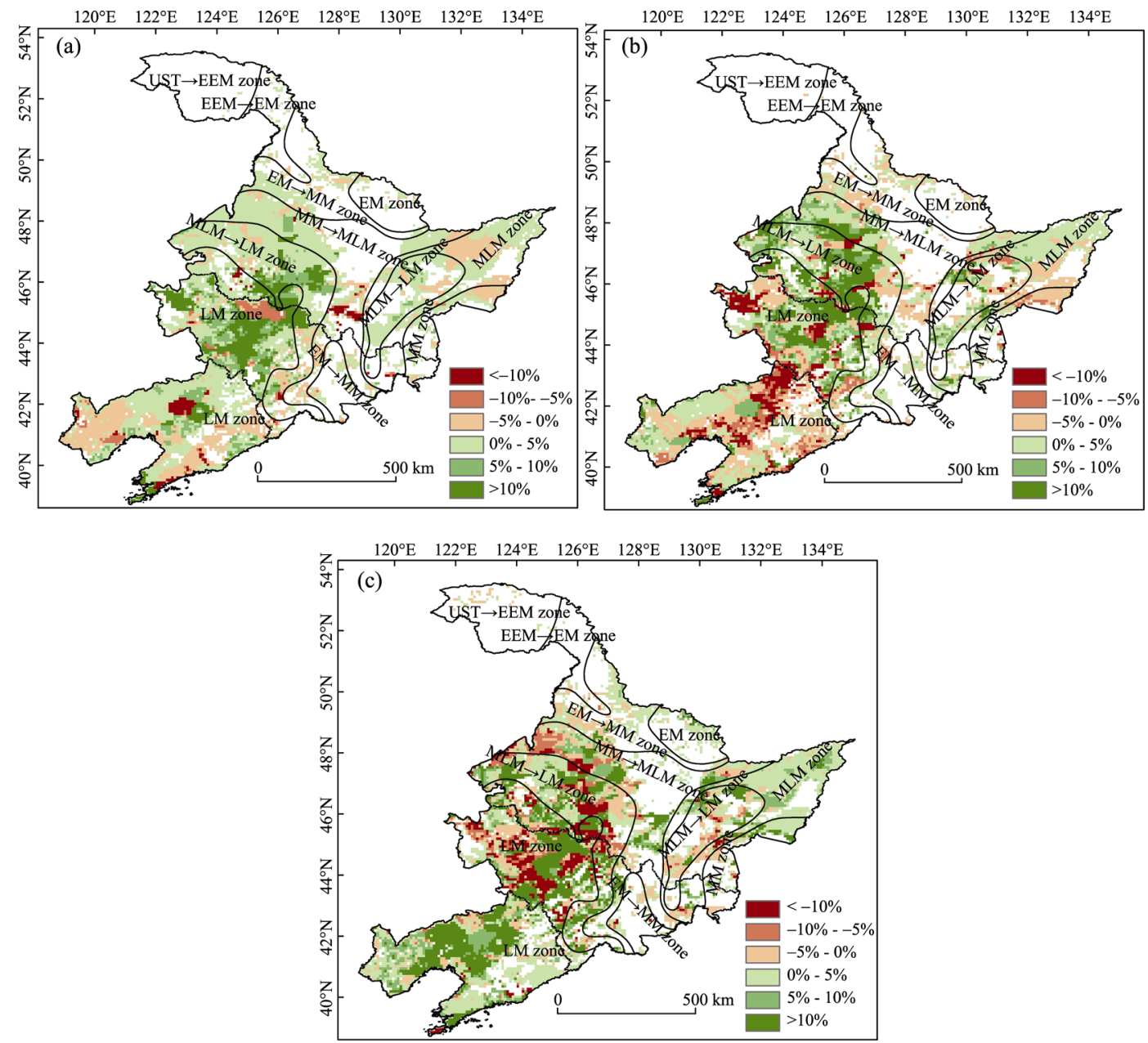

Figure 6 Dynamics of maize spatial distribution in different zones of maize maturity types in the 1980s (a), 1990s (b), and 2000s (c) 
During the 1990s, the area under maize increased mostly in the MLM $\rightarrow$ LM transitional zone in central-southern and eastern parts of Heilongjiang, but also in the MM $\rightarrow$ MLM transitional zone (Figure 6b). Of the total increase of approximately 0.84 million ha, the stable zones contributed roughly $16.5 \%$; of the rest, the major share was of the MLM $\rightarrow$ LM transitional zone $(63 \%)$, and the MM $\rightarrow$ MLM transitional zone contributed $16.5 \%$.

Since 2000 , the area under maize has been expanding rapidly, predominantly in the stable zone, which has contributed $75 \%$ of the total increase of about 2.8 million ha (Figure $6 \mathrm{c}$ ). The major is concentrated in the LM zone in mid-western Liaoning, central Jilin, and eastern Heilongjiang, with the MM $\rightarrow$ MLM zone contributing $11 \%$ and the MLM $\rightarrow$ LM transitional zone, slightly over $13 \%$. Thus during the last decade the expansion has been faster in the stable zone but slower in the transitional zones.

\section{Discussion}

The increasingly warmer climate makes it possible to grow new maize cultivars with a longer growing period. The northern limit of late-maturing, mid-late maturing, and mid-maturing cultivars in NEC has been pushed further by more than $150 \mathrm{~km}$, representing a $20 \%-30 \%$ increase in the area, whereas the area suitable for early-maturing cultivars in the north has shrunk and now accounts for less than $10 \%$ (Figure 2). Maize cultivation now extends to the northern part of the Lesser Khingan Mountains (Figure 6c), which represent the northern limit for the early-maturing maize cultivars (Liu Z J et al., 2013). More than 80\% of the increased area lies where AAT is $2800-3400{ }^{\circ} \mathrm{C} \cdot \mathrm{d}-$ a clear demonstration of the connection between expansion of the maize-growing area and the rising temperatures (Tao et al., 2008a, 2008b; Yang et al., 2015).

The results also show that in the northern part of NEC, where the increase in temperatures has rendered the area unsuitable for the extremely-early maturing cultivars, they can be replaced with the early-maturing cultivars. The fact that yields of late-maturing cultivars are higher than those of the early-maturing and mid-maturing cultivars has promoted these changes in the spatial distribution of maize. Additionally, farmers have gradually adjusted the sowing and harvesting dates to fully exploit the positive effects of the warmer weather on maize production (Li et al., 2014; Tao et al., 2014). The extended growing period and the expanding area show the agronomic adjustment of maize in NEC. The results also demonstrate that maize-based cropping systems have a great potential to adapt to the ongoing climate change, which may benefit future maize production, especially in northern areas.

The spatial distribution of maize in NEC changed dramatically as a result of climate change during the research period. In particular, we found temperature has a clear spatial influence on the relocation of maize production. Climate warming in the north pushed the maize production frontier northwards and farmers changed their maize cultivars in response to the changing climate. However, the influence of precipitation was less spatially coherent than temperature, because irrigation compensated for rainfall deficiencies. We are aware that the annual precipitation of 400-1000 $\mathrm{mm}$ in NEC, although adequate for maize growth and development, is not enough to compensate for the increase in evapotranspiration caused by warming (Tao et al., 2011): if water is insufficient during the growth period of maize, pro- 
duction will be adversely affected in rain-fed areas. Furthermore, a strong annual variation in temperature and precipitation was observed in NEC over the period covered (Chen et al., 2011), which means that extreme weather events (such as very low temperatures and drought) are likely to be more frequent in the region and can limit the area under maize (Liu et al., 2009; Zhang et al., 2012). Further research is therefore required to ascertain the causes of the changes in the spatial distribution of maize to take into account such factors as the impacts of changes in precipitation.

\section{Conclusions}

This study illustrates the effect of rising temperatures, a part of climate change, on the spatial distribution of maize in NEC from 1980 to 2010. The higher temperatures extended the duration of the growth of maize by advancing the date of sowing and extending the date of harvesting. The changed distribution of maize probably reflects successful adaptation to the warming witnessed over the recent decades. However, the actual expansion in area did not always occur in areas that had recorded higher temperatures. Maize is important and will continue to be important to China's food security. However, the expansion of area under maize in NEC faces some limitations. For example, expanding it without water management can destroy the ecosystem in surrounding areas. We advise the following research priorities and policy reforms in order to ensure food security.

(1) Reduce the risk of adverse impacts of the changes in temperature by taking suitable proactive adaptation measures such as adjusting the date of sowing and of harvesting, using maize cultivars with greater resistance to high or low temperatures, and adopting better agronomic practices to cope with biotic or abiotic sources of stresses.

(2) Focus on policies that promote more efficient management of water since the resource is limited, and expanding the area under maize may affect the water supplies required for maintaining the ecosystem.

(3) Accord higher priority to, and increase the funding for, more extensive research on the adaptability of agriculture to climate change in general and that of maize-based systems in particular, given the extended lag between investing on agricultural R\&D and reaping the benefits from that investment.

\section{References}

Anderson W, You L, Wood S et al., 2015. An analysis of methodological and spatial differences in global cropping systems models and maps. Global Ecology and Biogeography, 24: 180-191.

Carter T, Saarikko R, Niemi K, 1996. Assessing the risks and uncertainties of regional crop potential under a changing climate in Finland. Agricultural and Food Science 3: 329-349.

Chen C, Lei C, Deng A et al., 2011. Will higher minimum temperatures increase corn production in Northeast China? An analysis of historical data over 1965-2008. Agricultural and Forest Meteorology, 151: 1580-1588.

Chen C, Qian C, Deng A et al., 2012. Progressive and active adaptations of cropping system to climate change in Northeast China. European Journal of Agronomy, 38: 94-103.

CMA Archives, 2010. Chinese Meteorological Administration Archives. http://cdc.cma.gov.cn/.

De Jong R, Li K, Bootsma A et al., 2001. Crop yield variability under climate change and adaptive crop management scenarios, Final Report For Climate Change Action Fund Project A080, Eastern Cereal and Oilseed Research Centre (ECORC), Agric and Agri-Food Canada. 
Dixon R, Smith J, Guill S, 2003. Life on the edge: Vulnerability and adaptation of african ecosystems to global climate change. Mitigation and Adaptation Strategies for Global Change, 8: 93-113.

Dong J, Liu J, Tao F et al., 2009. Spatio-temporal changes in annual accumulated temperature in China and the effects on cropping systems, 1980s to 2000. climate research, 40: 37-48.

Gao J, Liu Y, 2011. Climate warming and land use change in Heilongjiang Province, Northeast China. Applied Geography, 31: 476-482.

IPCC (Intergovernmental Panel on Climate Change), 2007. Climate Change 2007: Impacts, Adaptation And Vulnerability. Contribution of Working Group II to the Fourth Assessment Report of the Intergovernmental Panel on Climate Change. Cambridge: Cambridge University Press.

IPCC (Intergovernmental Panel on Climate Change), 2013. Climate Change 2013: The Physical Science Basis. Contribution of Working Group I to the Fifth Assessment Report of the Intergovernmental Panel on Climate Change. Cambridge: Cambridge University Press.

Jia J, Guo J, 2010. Effects of climate changes on maize yield in Northeast China. Agricultural Science and Technology, 11: 169-174.

Jin Z, Ge D, Zheng X et al., 1996. Assessing the potential impacts of global climate change on maize production in China. Acta Agronomica Sinica, 22: 513-524.

Jin Z, Zhu D, 2008. Impacts of changes in climate and its variability on food production in Northeast China. Acta Agronomica Sinica, 34: 1588-1597.

Kenny G J, Harrison P A, Olesen J E et al., 1993. The effects of climate change on land suitability of grain maize, winter wheat and cauliflower in Europe. European Journal of Agronomy, 2: 325-338.

Li Z, Liu Z, Anderson W et al., 2015. Chinese rice production area adaptations to climate changes, 1949-2010. Environmental Science \& Technology, 49: 2032-2037.

Li Z, Tang H, Yang P et al., 2012. Spatio-temporal responses of cropland phenophases to climate change in Northeast China. Journal of Geographical Sciences, 2012, 22(1): 29-45.

Li Z, Yang P, Tang H et al., 2014. Response of maize phenology to climate warming in Northeast China between 1990 and 2012. Regional Environment Change, 14: 39-48.

Liu B, Xu M, Henderson M et al., 2004. Taking China's temperature: Daily range, warming trends, and regional variations, 1955-2000. Journal of Climate, 17: 4453-4462.

Liu J, Liu M, Deng X et al., 2002. The land use and land cover change database and its relative studies in China. Journal of Geographical Sciences, 12(2): 275-282.

Liu Z, Yang X, Wang W et al., 2009. Characteristics of agricultural climate resources in three provinces of Northeast China under global climate change. Chinese Journal of Applied Ecology, 20(9): 2199-2206. (in Chinese)

Liu Z H, Li Z, Tang P et al., 2013. Changes analysis of rice area and production in China during the past three decades. Journal of Geographical Sciences, 2013, 23(6): 1005-1018.

Liu Z J, Yang X, Chen F et al., 2013. The effects of past climate change on the northern limits of maize planting in Northeast China. Climatic Change, 117: 891-902.

Lobell D B, Burke M B, Tebaldi C et al., 2008. Prioritizing climate change adaptation needs for food security in 2030. Science, 319: 607-610.

Lobell D B, Schlenker W, Costa-Roberts J, 2011. Climate trends and global crop production since 1980. Science, 333: 616-620.

Monfreda C, Ramankutty N, Foley J A, 2008. Farming the planet: 2. Geographic distribution of crop areas, yields, physiological types, and net primary production in the year 2000. Global Biogeochemical Cycles, 22: B1022.

NBSC (National Bureau of Statistics of China), 2010. Statistical Yearbook of China 2010. Beijing: China Statistics Press. (in Chinese)

Nicholls N, 1997. Increased Australian wheat yield due to recent climate trends. Nature, 387: 484-485.

Ogden A E, Innes J L, 2008. Climate change adaptation and regional forest planning in southern Yukon, Canada. Mitigation and Adaptation Strategies for Global Change, 13: 833-861.

Olesen J E, Bindi M, 2002. Consequences of climate change for European agricultural productivity, land use and policy. European Journal of Agronomy, 16: 239-262.

Piao S, Ciais P, Huang Y et al., 2010. The impacts of climate change on water resources and agriculture in China. 
Nature, 467: 43-51.

PINC Archives, 2010. Planting Information Network of China. http://zzys.agri.gov.cn/nongqing.aspx.

Portmann F T, Siebert S, Döll P, 2010. MIRCA2000: Global monthly irrigated and rainfed crop areas around the year 2000: A new high-resolution data set for agricultural and hydrological modeling. Global Biogeochemical Cycles, 24: B1011.

Ramankutty N, Evan A T, Monfreda C et al., 2008. Farming the planet: 1. Geographic distribution of global agricultural lands in the year 2000. Global Biogeochemical Cycles, 22: B1003.

Sun W, Huang Y, 2011. Global warming over the period 1961-2008 did not increase high-temperature stress but did reduce low-temperature stress in irrigated rice across China. Agricultural and Forest Meteorology, 151: 1193-1201.

Tan J, Yang P, Liu Z et al., 2014a. Spatio-temporal dynamics of maize cropping system in Northeast China between 1980 and 2010 by using spatial production allocation model. Journal of Geographical Sciences, 24(3): 397-410.

Tan J, Li Z, Yang P et al., 2014b. Spatial evaluation of crop maps by the spatial production allocation model in China. Journal of Applied Remote Sensing, 8: 85197.

Tao F, Hayashi Y, Zhang Z et al., 2008a. Global warming, rice production, and water use in China: Developing a probabilistic assessment. Agricultural and Forest Meteorology, 148: 94-110.

Tao F, Yokozawa M, Liu J et al., 2008b. Climate-crop yield relationships at provincial scales in China and the impacts of recent climate trends. Climate Research, 38: 83-94.

Tao F, Yokozawa M, Xu Y et al., 2006. Climate changes and trends in phenology and yields of field crops in China, 1981-2000. Agricultural and Forest Meteorology, 138: 82-92.

Tao F, Zhang S, Zhang Z et al., 2014. Maize growing duration was prolonged across China in the past three decades under the combined effects of temperature, agronomic management, and cultivar shift. Global Change Biology, 20: 3686-3699.

Tao F, Zhang Z, 2010. Adaptation of maize production to climate change in North China Plain: Quantify the relative contributions of adaptation options. European Journal of Agronomy, 33: 103-116.

Tao F, Zhang Z, 2011. Impacts of climate change as a function of global mean temperature: Maize productivity and water use in China. Climatic Change, 105: 409-432.

Xiao X, Boles S, Liu J et al., 2005. Mapping paddy rice agriculture in southern China using multi-temporal MODIS images. Remote Sensing of Environment, 95: 480-492.

Yang X, Chen F, Lin X et al., 2015. Potential benefits of climate change for crop productivity in China. Agricultural and Forest Meteorology, 208: 76-84.

Yang X, Lin E, Ma S et al., 2007. Adaptation of agriculture to warming in Northeast China. Climatic Change, 84: $45-58$.

You L, Wood S, 2006. An entropy approach to spatial disaggregation of agricultural production. Agricultural Systems, 90: 329-347.

You L, Rosegrant M W, Wood S et al., 2009a. Impact of growing season temperature on wheat productivity in China. Agricultural and Forest Meteorology, 149: 1009-1014.

You L, Wood S, Wood-Sichra U, 2009b. Generating plausible crop distribution maps for Sub-Saharan Africa using a spatially disaggregated data fusion and optimization approach. Agricultural Systems, 99: 126-140.

You L, Wood S, Wood-Sichra U et al., 2014. Generating global crop distribution maps: From census to grid. Agricultural Systems, 127: 53-60.

Zhang Q, Sun P, Singh V P et al., 2012. Spatial-temporal precipitation changes (1956-2000) and their implications for agriculture in China. Global and Planetary Change, 82/83: 86-95.

Zhang Z, Wang X, Zhao X et al., 2014. A 2010 update of National Land Use/Cover Database of China at 1:100000 scale using medium spatial resolution satellite images. Remote Sensing of Environment, 149: $142-154$. 